\title{
Candida Species Distribution of Clinical Specimens in Banda Aceh, Indonesia
}

\author{
Suhartono Suhartono $^{1 *}$, Wilda Mahdani ${ }^{2}$, Aderiana Masthura ${ }^{1}$, Iman Rusmana ${ }^{3}$ \\ ${ }^{1)}$ Department of Biology, Faculty of Mathematics and Natural Sciences, Universitas Syiah Kuala, Indonesia \\ ${ }^{2}$ Microbiology Departement of Medical Faculty, Universitas Syiah Kuala, Indonesia. \\ ${ }^{3)}$ Departement of Biology, Faculty of Mathematics and Natural Sciences, IPB University, Indonesia. \\ *Email: suhartono@unsyiah.ac.id
}

Submitted: 15 March 2020. Revised: 23 May 2020. Accepted: 7 July 2020

\begin{abstract}
Candidiasis has become increasingly widespread in the community alongside with the developing resistance of Candida sp. to some antifungals. A prevalence study in the present research is required to surveil the distribution of Candida-related infections to administrate the appropriate antifungal treatments. The objective of this research was to determine the species distribution of candidiasis with their antifungal susceptibility isolated from clinical specimens at the Zainoel Abidin Hospital (ZAH) Banda Aceh, Indonesia. The clinical specimens were from inpatients and outpatients in the hospital during January to June 2019. The identification of Candida species and antifungal sensitivity assay were conducted by using VITEK ${ }^{\circledR} 2$ Compact. Of a total of 68 isolates, there were six species of Candida with the highest species prevalence was Candida tropicalis $(52.94 \%)$. Additionally, the highest prevalence of candidiasis came from urine specimen $(54.41 \%)$ and mostly from inpatients in the internal medicine unit $(54.41 \%)$. Candidiasis occurred predominantly in men $(58.82 \%)$ and during adulthood $(55.88 \%)$. The antibiogram of Candida sp. shows a high percentage of sensitivity towards some antifungals including fluconazole (100\%), voriconazole (100\%), caspofungin (100\%), micafungin (100\%), amphotericin B (99.5\%), and flucytosine (100\%). From this result, it can be concluded that candidiasis cases in the ZAH Banda Aceh, Indonesia has prevalently occurred with the few antifungal therapies for candidiasis of were still effective empirically and definitively. This is an initial study of Candida prevalence within different clinical samples in Banda Aceh and the study is expected to be a basis for prevention and control of Candida-related infections in the area.
\end{abstract}

Key words: Candidiasis; Fungal Susceptibility; Species Distribution

How to Cite: Suhartono, S., Mahdani, W., Masthura, A., \& Rusmana, I. (2020). Candida Species Distribution of Clinical Specimens in Banda Aceh, Indonesia. Biosaintifika: Journal of Biology \& Biology Education, 12 (2), 262-267

DOI: http://dx.doi.org/10.15294/biosaintifika.v12i2.23758

\section{INTRODUCTION}

Candidiasis is still a major concern due to its increasing rate of infections ranging from superficially topical infections (Frías-De-León et al., 2019) to serious systemic infections (Mavor et al., 2005) in community as well as hospital settings. The infection mainly caused by opportunistic fungal species of Candida sp. which are normally parts of microflora in human gastrointestinal, urogenital, and skins (Martins et al., 2014). Depending on the environmental conditions, the fungal pathogen is able to reversibly switch between two morphological forms as yeast-like form or filamentous form (pseudohyphae) contributing to the major virulence of the pathogen, including by means of biofilm formation (Tsui et al., 2016). Candidiasis predominantly affects individuals who have compromised immune status after administration of immunosuppressant drugs for the patients requiring organ transplantation or suffering from cancer (Sanguinetti et al., 2015; Karasuno et al., 2019).

The most primary prescribed antifungal drugs to treat candidiasis, including in the Zainoel Abidin Hospital (ZAH) is from the groups of azoles, predominantly as fluconazole. This antifungal inhibits ergos- terol biosynthesis, a major component of fungal cell wall, by blocking $14 \alpha$-demethylase (Erg11p or Cyp51p), leading to ergosterol depletion and decreasing membrane rigidity as well as increasing drug uptakes (Sorgo et al., 2011). The intensive use of antifungal drugs including fluconazole might lead the fungal pathogen to develop its resistance (Berkow \& Lockhart, 2017; Deorukhkar \& Roushani, 2017). A study of prevalence, i.e. number of particular infections occurring in the particular times within population, is essential to determine appropriate treatments, including antifungal administration. Hence, the study for determination of fungal pathogens causing particular infection as well as their sensitivity towards antifungal is required to ensure the appropriate treatments in terms of types and dose of antifungals.

During June-July 2018, there was an emerging detection on Candida sp. from the clinical specimens in the ZAH. The prevalence and antifungal susceptibility of the Candida infections at the $\mathrm{ZAH}$, however, is limited. Therefore, the objectives of the paper were to determine the species distribution of Candida sp. responsible for candidiasis in the $\mathrm{ZAH}$, based on types of clinical specimens, wards, gender, and age of the patients as well as to evaluate the susceptibility of 
the fungal pathogens to prevent and control the fungal infections in the hospital.

\section{METHODS}

\section{Clinical specimen collection and preparation}

The fungal pathogens were isolated from the sixtyeight clinical samples of inpatients and outpatients patients at the ZAH Banda Aceh, Indonesia during the period of January to June 2019. The clinical samples consisted of blood $(n=11)$, urines $(n=37)$, sputum ( $\mathrm{n}=11)$, pus $(\mathrm{n}=5)$, ascites fluids $(\mathrm{n}=1)$, and swabs of ear $(n=2)$ and vagina $(n=1)$. All the samples were recorded for the types of clinical samples, ages, sexes, and types of ward. Blood samples. particularly, were initially transferred and pre-incubated at $37^{\circ} \mathrm{C}$ before in culture flasks of BacT/ALERT $^{\circledR}$ 3D (BacT/ALERT ${ }^{\circledR}$ FA Plus) prior further isolation using culture media.

\section{Microscopic observation and antifungal suscepti- bility assays}

All clinical samples were inoculated to plates containing culture media of blood agar (Merck, Germany) and MacConkey agar (Merck, Germany) using inoculation loop of $1 \mu \mathrm{L}$ for urine samples and $10 \mu \mathrm{L}$ for other than urine samples. The plates were then incubated for 24 hours at $37{ }^{\circ} \mathrm{C}$ before they were Gram-stained and macroscopically and microscopically observed for morphological features. Moreover,

additional identification as well as antibiotic resistance profiles, were generated using VITEK $^{\circledR} 2$ Compact (Biomeriux, Lyon, France). A pure Candida colony recovered from the clinical samples was suspended in $\mathrm{NaCl} 0.45 \%$ equivalent to $1.8-2.2$ McFarland Standard solution before the suspension was inoculated into cassettes of YST (yeast) and AST (antimicrobial susceptibility testing) for identification and antifungal susceptibility, respectively.

\section{Data analysis}

The species distribution of Candida sp. was descriptively analyzed based on types of clinical specimens, wards, gender, and age of the patients. The research has been approved for ethical clearance from the Ethical Clearance Committee for Health Research, Faculty of Medicine, Universitas Syiah Kuala with registration number 70/EA/FK-RSUDZA/2019.

\section{RESULTS AND DISCUSSION}

A total of 68 Candida sp. isolates were recovered during the study. The isolates were able to grow on the blood but unable to grow on MacConkey agar as the initial characteristics of yeast cells. The isolates on the agar showed morphological features of small, round, raised, and creamy colonies (Figure 1a). Based on microscopic observation, the yeast had positive gram staining with rice-like shaped cells, i.e. as yeast form (Figure 1b), or filamentous form (Figure 1c).

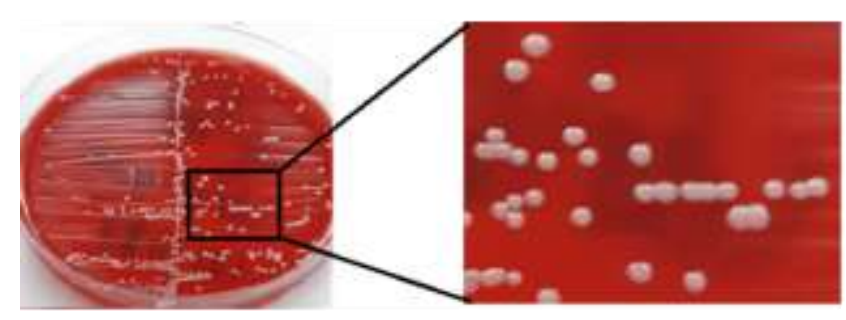

(a)

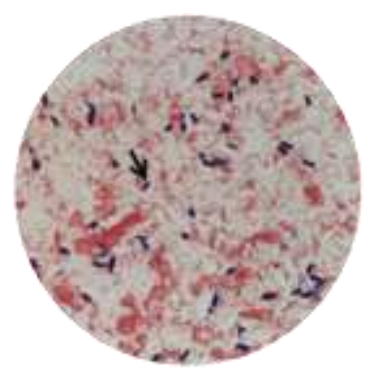

(b)

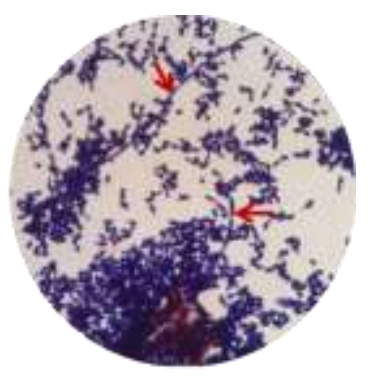

(c)

Figure 1. The morphological features of Candida sp. recovered from clinical specimens at the Zainoel Abidin hospital in Banda Aceh, Indonesia (a) colonies grown on the blood agar; (b) positive gram staining with ricelike shaped cells (black arrow) from direct observation of sputum with 1,000X magnification, and (c) morphological form of the fungal pathogen as yeast cells and filaments or pseudohyphae (red arrows) with 1,000X magnification.

Despite the fact that Candida sp is parts of human microflora mainly residing in the gastrointestinal and urinary tracts as well as skins, the fungi can switch from a harmless commensal to pathogens by expressing a set of virulence factors leading to candidiasis depending on the host immune status (Calderone \& Fonzi, 2001). The switching might be indicated by changing the formation from unicellular yeast cells to filamentous hyphal form (Singh et al., 2015). In this research, the occurrence of Candida infections was observed by both culturing and direct microscopy approaches. Figure 1 shows the typical morphological characteristics of Candida sp. isolates growing on blood agar with small round creamy colonies and appeared as dark blue after Gram-staining (Byadarahally Raju \& Rajappa, 2011). Also, Figure 1c shows the pseudohyphae form of the Candida sp. during the study which is commonly formed at specific environmental conditions subsequently affecting a delay 
in both cell-cycle progression and extension of the apical growth period (Bravo Ruiz et al., 2020).

Table 1 shows that Candida tropicalis and Candida albicans were the two most dominant species responsible for $52.94 \%$ and $30.88 \%$ of candidiasis, respectively, detected in the clinical specimens of the ZAH. The other species found in this research were
C. famata, C. lucitaniae, C. ciferrii, and C. rugosa. Based on the types of wards or patient care units, candidiasis predominantly occurred in the patients from internal medicine wards accounting for more than half of the infections during the study (Table 1) with all five Candida sp. were found in the clinical samples collected from the unit.

Table 1. Species distribution of Candida sp. responsible for candidiasis relative to the types of hospital wards during a period of January-June 2019 in the Zainoel Abidin Hospital, Banda Aceh, Indonesia

\begin{tabular}{|c|c|c|c|c|c|c|c|}
\hline \multirow{2}{*}{ Type of wards } & \multicolumn{6}{|c|}{ Candida species } & \multirow{2}{*}{$\begin{array}{l}\text { Total per } \\
\text { wards }\end{array}$} \\
\hline & C. tropicalis & C. albicans & C. famata & C. lucitaniae & C. ciferrii & C. rugosa & \\
\hline Intensive care unit & $12(17.65 \%)$ & $3(4.41 \%)$ & - & - & - & - & $15(22.06 \%)$ \\
\hline Internal medicine unit & $16(23.53 \%)$ & $14(20.59 \%)$ & $3(4.41 \%)$ & $2(2.94 \%)$ & $1(1.47 \%)$ & $1(1.47 \%)$ & $37(54.41 \%)$ \\
\hline Surgical unit & $4(5.88 \%)$ & $3(4.41 \%)$ & $3(4.41 \%)$ & - & $1(1.47 \%)$ & - & $11(16.18 \%)$ \\
\hline Neurological unit & $3(4.41 \%)$ & - & - & - & - & - & $3(4.41 \%)$ \\
\hline Outpatient unit & $1(1.47 \%)$ & $1(1.47 \%)$ & - & - & - & - & $2(2.94 \%)$ \\
\hline Total per species & $36(52.94 \%)$ & $21(30.88 \%)$ & $6(8.82 \%)$ & $2(2.94 \%)$ & $2(2.94 \%)$ & $1(1.47 \%)$ & $68(100 \%)$ \\
\hline
\end{tabular}

The most prevalence of Candidiasis in this study occurred in the internal medicine unit accounting for $54.41 \%$ (Table 1). This might be due to the utilization of catheters or other prosthetic devices in addition to the intrinsic factors of the patients. The previous study signified that Candida sp. had ability to form biofilm in the invasive medical devices, including catheters allowing the fungal pathogen to adhere and reside resulting in increasing high mortality rate (Nett, 2016; Tsui et al., 2016; Vitális et al., 2020). In the form of biofilm, the fungal pathogen might resist the host immune response and express some virulent factors which differ from the properties of the planktonic forms (Bouza et al., 2015). Other researchers found that $C$. tropicalis was determined to have highest biofilm formation ability compared to other high biofilm-forming Candida isolates, such as C. parapsilosis, C. glabrata, and C. orthopsilosis (Sahal \& Bilkay, 2018).

In terms of gender, candidiasis was more prevalent in men than in women (Table 2). This might be associated with the fact that during January-June 2019, there were more clinical specimens from men patients than women accounting for $53.95 \%$ and $46.05 \%$, respectively, from the total 3.168 patients (data not shown). Other investigators argued that the occurrence of candidiasis between men and women is equal since Candida sp. reside as normal flora in both men and women as demonstrated in their research in Korea (Kim et al., 2016; Shin et al., 2010).

Among age groups, it is found that in the present study candidiasis prevalently occurred during adulthood $(55.88 \%)$ (Table 3$)$ of the total infections during the study. Candidiasis was prevalent in patients age 19-59 years and patients age $\geq 60$ accounting for $55.88 \%$ and $41.18 \%$, respectively. Teenagers age of 13-18 years, however, had no candidiasis detected in their clinical specimens during the period of study. These findings are also supported by previous research (Kim et al., 2016) indicating that the infection rate of candidiasis tends to increase with increasing age. It is argued that this might be related to immune status since there is a progressive decline of the total lymphocyte and absolute number of $\mathrm{T}$ and $\mathrm{B}$ cells among age groups from infants to adults (Valiathan et al., 2016).

Moreover, in terms of types of clinical specimens, Table 4 shows that most of candidiasis occurred in the urine samples accounting more than half of candidiasis occurrence during a period of study. Of 37 urine samples, Candida tropicalis and Candida albicans was predominantly found in $17(46 \%)$ and $12(32 \%)$ samples, respectively. This result is in alignment with the previous study signifying the presence of Candida $s p$. in urine, blood, and sputum from the university hospital in Korea that were disseminated through nosocomial infections mediated by intensive use of catheter and improper use of antimicrobial therapy (Kim et al., 2016). Furthermore, some predisposing factors, including diabetes mellitus, are more likely to trigger the Candida sp. to switch from commensal to pathogenic forms due to the increasing blood sugar level in urine and blood along with decreasing host immune (Esmailzadeh et al., 2018; Wantini \& Rani, 2017). 
Table 2. Species distribution of Candida sp. responsible for candidiasis based on gender during a period of January-June 2019 in the Zainoel Abidin Hospital, Banda Aceh, Indonesia

\begin{tabular}{llllllll}
\hline \multirow{2}{*}{ Sexes } & \multicolumn{5}{c}{ Candida species } & \multirow{2}{*}{ Total per sexes } \\
\cline { 2 - 7 } & C. tropicalis & C. albicans & C. famata & C. lucitaniae & C. ciferrii & C. rugosa & \\
\hline Females & $14(20.59 \%)$ & $11(16.18 \%)$ & $2(2.94 \%)$ & $1(1.47 \%)$ & - & - & $28(41.18 \%)$ \\
Males & $22(32.35 \%)$ & $10(14.71 \%)$ & $4(5.88 \%)$ & $1(1.47 \%)$ & $2(2.94 \%)$ & $1(1.47 \%)$ & $40(58.82 \%)$ \\
Total & $36(52.94 \%)$ & $21(30.88 \%)$ & $6(8.82 \%)$ & $2(2.94 \%)$ & $2(2.94 \%)$ & $1(1.47 \%)$ & $68(100 \%)$ \\
\hline
\end{tabular}

Table 3. Species distribution of Candida sp. responsible for candidiasis based on age groups during a period of January-June 2019 in the Zainoel Abidin Hospital, Banda Aceh, Indonesia

\begin{tabular}{lccccccc}
\hline \multirow{2}{*}{ Age groups (years) } & \multicolumn{5}{c}{ Candida species } & \multicolumn{2}{c}{ Total per age } \\
\cline { 2 - 6 } & C. tropicalis & C. albicans & C. famata & C. lucitaniae & C. ciferrii & C. rugosa & $\begin{array}{c}\text { group } \\
\text { 0-12 }\end{array}$ \\
$13(1.47 \%)$ & - & - & - & - & $1(1.47 \%)$ & - & $2(2.94 \%)$ \\
$13-18$ & - & - & - & - & - & - \\
$19-59$ & $18(26.47 \%)$ & $13(19.12 \%)$ & $5(7.35 \%)$ & $1(1.47 \%)$ & $1(1.47 \%)$ & - & $38(55.88 \%)$ \\
$\geq 60$ & $17(25.00 \%)$ & $8(11.76 \%)$ & $1(1.47 \%)$ & $1(1.47 \%)$ & - & $1(1.47 \%)$ & $28(41.18 \%)$ \\
Total per species & $36(52.94 \%)$ & $21(30.88 \%)$ & $6(8.82 \%)$ & $2(2.94 \%)$ & $2(2.94 \%)$ & $1(1.47 \%)$ & $68(100 \%)$ \\
\hline
\end{tabular}

Table 4. Species distribution of Candida sp. responsible for candidiasis relative to the types of clinical specimen during a period of January-June 2019 in the Zainoel Abidin hospital, Banda Aceh, Indonesia

\begin{tabular}{|c|c|c|c|c|c|c|c|}
\hline \multirow{2}{*}{ Clinical specimens } & \multicolumn{6}{|c|}{ Candida species } & \multirow{2}{*}{$\begin{array}{l}\text { Total per speci- } \\
\text { mens }\end{array}$} \\
\hline & C. tropicalis & C. albicans & C. famata & C. lucitaniae & C. ciferrii & C. rugosa & \\
\hline Urine & $17(25 \%)$ & $12(17.65 \%)$ & $4(5.88 \%)$ & $2(2.94 \%)$ & $1(1.47 \%)$ & $1(1.47 \%)$ & $37(54.41 \%)$ \\
\hline Blood & $7(10.29 \%)$ & $3(4.41 \%)$ & $1(1.47 \%)$ & - & - & - & $11(16.18 \%)$ \\
\hline Sputum & $7(10.29 \%)$ & $3(4.41 \%)$ & $1(1.47 \%)$ & - & - & - & $11(16.18 \%)$ \\
\hline Pus & $3(4.41 \%)$ & $2(2.94 \%)$ & - & - & - & - & $5(7.35 \%)$ \\
\hline Ear Swabs & $1(1.47 \%)$ & - & - & - & $1(1.47 \%)$ & - & $2(2.94 \%)$ \\
\hline Ascites fluids & $1(1.47 \%)$ & - & - & - & - & - & $1(1.47 \%)$ \\
\hline Vaginal swabs & - & $1(1.47 \%)$ & - & - & - & - & $1(1.47 \%)$ \\
\hline Total per species & $36(52.94 \%)$ & $21(30.88 \%)$ & $6(8.82 \%)$ & $2(2.94 \%)$ & $2(2.94 \%)$ & $1(1.47 \%)$ & $68(100 \%)$ \\
\hline
\end{tabular}

Table 5. Antifungal sensitivity (\%) of Candida sp. responsible for candidiasis isolated from clinical specimens during a period of January-June 2019 in the Zainoel Abidin Hospital, Banda Aceh, Indonesia

\begin{tabular}{|c|c|c|c|c|c|c|c|}
\hline \multirow{2}{*}{ Species } & \multirow{2}{*}{ (n) } & \multicolumn{6}{|c|}{ Percentage of Antifungals Sensitivity (MIC in $\mu \mathrm{g} / \mathrm{mL}$ ) } \\
\hline & & FCZ & VRC & $\mathrm{CPF}$ & $\mathrm{MCF}$ & ApB & FY \\
\hline Cand & 36 & 100( & 10 & ) & 10 & 97 & 10 \\
\hline Candida albicans & 21 & $100(0.5)$ & $100(0.12)$ & $100(0.12)$ & $100(0.06)$ & $100(0.54)$ & $100(1.00)$ \\
\hline Candida famata & 6 & $100(\mathrm{n} / \mathrm{a})$ & $100(\mathrm{n} / \mathrm{a})$ & $100(\mathrm{n} / \mathrm{a})$ & $100(\mathrm{n} / \mathrm{a})$ & $100(\mathrm{n} / \mathrm{a})$ & $100(\mathrm{n} / \mathrm{a})$ \\
\hline Candida lucitaniae & 2 & $100(\mathrm{n} / \mathrm{a})$ & $100(0.12)$ & $100(\mathrm{n} / \mathrm{a})$ & $100(\mathrm{n} / \mathrm{a})$ & $100(0.5)$ & $100(\mathrm{n} / \mathrm{a})$ \\
\hline Candida ciferrii & 2 & 100 (n/a) & $100(\mathrm{n} / \mathrm{a})$ & $100(\mathrm{n} / \mathrm{a})$ & $100(\mathrm{n} / \mathrm{a})$ & $100(\mathrm{n} / \mathrm{a})$ & $100(\mathrm{n} / \mathrm{a})$ \\
\hline Candida rugosa & 1 & $100(\mathrm{n} / \mathrm{a})$ & $100(0.12)$ & $100(\mathrm{n} / \mathrm{a})$ & $100(\mathrm{n} / \mathrm{a})$ & $100(\mathrm{n} / \mathrm{a})$ & $100(1.00)$ \\
\hline
\end{tabular}

Note: FCZ (Fluconazole); MCF (Micafungin); VRC (Voriconazole); ApB (Amphotericin B); CPF (Caspofungin); FY (Flucytosine); n/a: data not available

In terms of antimicrobial susceptibility, the assay test showed that the sensitivity of the fungal pathogens across the Candida species against the antifungals (fluconazole, voriconazole, caspofungin, micafungin, amphotericin $\mathrm{B}$, and flucytosine) was still high, i.e., more than $97 \%$, meaning that the antifungals were still effective to treat the fungal infections (Table 5). In this study, C. tropicalis and C. albicans were the two-most predominant Candida sp. found in the clinical specimens. This result is quite different from previous studies stating that $C$. albicans was the most prevalent species followed by $C$. tropicalis in Korea (Kim et al., 2016). This difference might be due to the variations of seasons, locations, as well as environmental settings (Kim et al., 2016). Other investigators (Zarrin \& Mahmoudabadi, 2009) argued that the increasing occurrence of non-albicans Candida, such as $C$. tropicalis, is due to the increasing administration of fluconazole which is potent to $C$. albicans but not to non-albicans. Additionally, in this study, the MIC values of $C$. tropicalis $(0.74 \mu \mathrm{g} / \mathrm{mL})$ was higher than $C$. albicans $(0.5 \mu \mathrm{g} / \mathrm{mL})$ (Table 5) leading to the elimination of the C. albicans was more likely to occur whereas $C$. tropicalis survived and remained colonializing during the empirical therapy 
of fluconazole explaining the more prevalence of $C$. tropicalis.

To monitor and evaluate the efficacy of antifungal administration for candidal infections, it is essential to assay the existing antifungals to determine the Candidal resistance during a period of time. In the antifungal susceptibility tests, the sensitivity percentage of Candida sp in this study was higher indicating that the fungal pathogens are still susceptible to the current antifungals, i.e. fluconazole, voriconazole, caspofungin, micafungin, amphotericin $\mathrm{B}$, and flucytosine. This finding is corroborated with previous study demonstrating that Candida sp. was still susceptible to fluconazole (Reza et al., 2017). In the ZAH, fluconazole is still the primary prescribed drug to treat candidiasis. Although $C$. tropicalis found as the most prevalent in the present study remained susceptible, however, other research reported the increasing trend of resistance of the fungal pathogen due to the expression a various virulent factors (Zuza-Alves et al., 2017) and robust biofilm-mediated infection (Sahal \& Bilkay, 2018).

This is the first work to elucidate the spread and the antifungal sensitivity of Candida sp responsible for candidiasis in the ZAH based on the types of patients ' clinical specimens, gender and age. This study is essential to provide benefits in taking infection prevention and control policies as well as in providing empirical antifungals to overcome Candida-related infections in clinical and communal settings.

\section{CONCLUSION}

Candidiasis cases in ZAH Banda Aceh were prevalently caused by Candida tropicalis with the highest occurrence from urine specimens, of inpatients in the internal medicine unit, men with age group of 19-59 years or older. Additionally, although the current antifungal therapy in the ZAH for candidiasis is considered still effective empirically and definitively, the surveillance of the fungal pathogens, especially Candida tropicalis, is still highly required to be monitored and implemented.

\section{ACKNOWLEDGEMENTS}

Authors acknowledged the Laboratory of Clinical Microbiology Installation of Integrated Clinical Laboratory of dr. Zainoel Abidin Hospital Banda Aceh, Indonesia for providing facilities during the study. Additionally, the Internship scientific publication program of FMIPA, Universitas Syiah Kuala was acknowledged for the composition of the paper.

\section{REFERENCES}

Berkow, E. L., \& Lockhart, S. R. (2017). Fluconazole resistance in Candida species: a current perspective. Infection and drug resistance, 10, 237-245.

Bouza, E., Guinea, J., \& Guembe, M. (2015). The role of antifungals against candida biofilm in catheterrelated candidemia. Antibiotics, 4(1), 1-17.

Bravo Ruiz, G., Ross, Z. K., Gow, N. A. R., \& Lorenz, A. (2020). Pseudohyphal growth of the emerging pathogen Candida auris is triggered by genotoxic stress through the $\mathrm{S}$ phase checkpoint. mSphere, 5(2), e00151-00120.

Byadarahally Raju, S., \& Rajappa, S. (2011). Isolation and identification of Candida from the oral cavity. ISRN dentistry, 2011.

Calderone, R. A., \& Fonzi, W. A. (2001). Virulence factors of Candida albicans. Trends in Microbiology, 9(7), 327-335.

Deorukhkar, S., \& Roushani, S. (2017). Fluconazole resistance in Candida Species: Ten year's experience at a rural tertiary care teaching hospital in India. Journal of Infectious Diseases and Pathogenesis, $1,102$.

Esmailzadeh, A., Zarrinfar, H., Fata, A., \& Sen, T. (2018). High prevalence of Candiduria due to nonalbicans Candida Species among diabetic patients: A matter of concern? Journal of Clinical Laboratory Analysis, 32(4), e22343.

Frías-De-León, M. G., Martínez-Herrera, E., AcostaAltamirano, G., Arenas, R., \& RodríguezCerdeira, C. (2019). Superficial candidosis by Candida duobushaemulonii: An emerging microorganism. Infection, Genetics and Evolution, 75, 103960 . doi:https://doi.org/10.1016/j.meegid.2019.103960.

Karasuno, T., Sata, H., Noda, Y., Imakita, M., \& Yasumi, M. (2019). Invasive candidiasis leading to gastric perforation in an immunocompromised patient. IDCases, 18, e00627.

Kim, G.-Y., Jeon, J.-S., \& Kim, J. K. (2016). Isolation frequency characteristics of Candida species from clinical specimens. Mycobiology, 44(2), 99-104.

Martins, N., Ferreira, I. C. F. R., Barros, L., Silva, S., \& Henriques, M. (2014). Candidiasis: Predisposing factors, prevention, diagnosis and alternative treatment. Mycopathologia, 177(5), 223-240.

Mavor, A. L., Thewes, S., \& Hube, B. (2005). Systemic fungal infections caused by Candida Species: Epidemiology, infection process and virulence attributes. Current Drug Targets, 6(8), 863874.

Nett, J. E. (2016). The host's reply to Candida biofilm. Pathogens, 5(1), 33. 
Reza, N. R., Tantari, S., \& Basuki, S. (2017). In vitro susceptibilty test of fluconazole to Candida spp in patients with oropharyngeal candidiasis and HIV/AIDS with Vitek II. Berkala Ilmu Kesehatan Kulit dan Kelamin, 29(3), 234-242.

Sahal, G., \& Bilkay, I. S. (2018). Distribution of clinical isolates of Candida spp. and antifungal susceptibility of high biofilm-forming Candida Isolates. Revista da Sociedade Brasileira de Medicina Tropical, 51, 644-650.

Sanguinetti, M., Posteraro, B., \& Lass-Flörl, C. (2015). Antifungal drug resistance among Candida species: Mechanisms and clinical impact. $M y$ coses, 58(S2), 2-13.

Shin, H.-S., Park, Y.-B., \& Shin, D.-S. (2010). Isolation frequency of Candida species from clinical specimens. The Korean Journal of Mycology, 38(2), 146-151.

Singh, S., Fatima, Z., \& Hameed, S. (2015). Predisposing factors endorsing Candida Infections. Le infezioni in medicina: rivista periodica di eziologia, epidemiologia, diagnostica, clinica e terapia delle patologie infettive, 23(3), 211-223.

Sorgo, A. G., Heilmann, C. J., Dekker, H. L., Bekker, M., Brul, S., de Koster, C. G., Klis, F. M. (2011). Effects of fluconazole on the secretome, the wall proteome, and wall integrity of the clinical fungus Candida albicans. Eukaryotic Cell, 10(8), 10711081.

Tsui, C., Kong, E. F., \& Jabra-Rizk, M. A. (2016). Pathogenesis of Candida albicans biofilm. Pathogens and Disease, 74(4).

Valiathan, R., Ashman, M., \& Asthana, D. (2016). Effects of ageing on the immune system: Infants to Elderly. Scandinavian Journal of Immunology, 83(4), 255-266.

Vitális, E., Nagy, F., Tóth, Z., Forgács, L., Bozó, A., Kardos, G., Kovács, R. (2020). Candida biofilm production is associated with higher mortality in patients with candidaemia. Mycoses, 63(4), 352360.

Wantini, S., \& Rani, T. S. (2017). Gambaran Jamur Candida albicans dalam urine penderita diabetes melllitus di RSUD Jendral Hamad Yani, Kota Metro. 2017, 5(2), 5.

Zarrin, M., \& Mahmoudabadi, A. Z. (2009). Invasive Candidiasis; a review article. Jundishapur Journal of Microbiology, 2(1), 1.

Zuza-Alves, D. L., Silva-Rocha, W. P., \& Chaves, G. M. (2017). An update on Candida tropicalis based on basic and clinical approaches. Frontiers in $\mathrm{Mi}$ crobiology, 8(1927). 